\title{
ASYMMETRIES IN UTILITY FUNCTIONS AND MARRIAGE DECISIONS: A RAMSEY-KOOPMANS APPROACH
}

\author{
ASIMETRIAS EN LA FUNCION DE UTILIDAD Y DECISIONES \\ MATRIMONIALES: UN ENFOQUE DE RAMSEY-KOOPMANS
}

\section{GONZALO EDWARDS*}

\begin{abstract}
This paper determines an empirical indicator for the cost of marrying a spouse with a different level of impatience or rate of time preference, and/or a different degree of aversion to intertemporal variability in consumption. Empirical data from different published sources are used to calibrate the model.
\end{abstract}

Keywords: Ramsey model, rate of time preference, marriage decision, value of impatience, value of risk aversion.

JEL Classification: $J 12, J 16$.

\section{Resumen}

Este artículo propone un indicador empírico del costo de casarse con un cónyuge con un nivel diferente de impaciencia o tasa de preferencia de tiempo, o un grado diferente de aversión a la variabilidad intertemporal

* Gonzalo Edwards is a professor at the Institute of Economics of Pontificia Universidad Católica de Chile. I thank Constanza Fosco, Iván Huerta, José López, Raimundo Soto, Felipe Zurita and the audience at the Sociedad de Economía de Chile (SECHI) Annual Seminar for helpful comments. Errors are, as usual, my responsibility.

E-mail: gedwards@uc.cl. 
en el consumo. Los datos empíricos de diferentes fuentes publicadas se utilizan para calibrar el modelo.

Palabras clave: Modelo de Ramsey, tasa de preferencia en el tiempo, decisión de matrimonio, valor de la impaciencia, valor de la aversión al riesgo.

Clasificación JEL: J12, J16.

\section{INTRODUCTION}

This paper analyzes, within a Ramsey-Koopmans framework, the cost, in economic terms, of marrying an individual with a different degree of impatience (pure rate of time preference) and/or a different degree of aversion to variability in consumption over time. This will be done considering consumption utility only, fully aware that there are many good reasons, unrelated to consumption trajectories, that give rise to the expression that "unlike poles attract each other".

Specifically, we will measure how much richer spouse-2 has to be in order to compensate for the cost, in terms of consumption utility, he/she imposes on spouse1 , due to his/her differences in the pure rate of time preference and/or the degree of relative aversion to variability in consumption over time.

We will assume a utility function at the individual level exhibiting a constant elasticity of marginal utility of consumption, which in an uncertainty context would typically imply a constant relative risk aversion coefficient ${ }^{1}$.

\section{THE SINGLE INDIVIDUAL}

Assume a single individual who is analyzing the decision of whether or not to get married. His/her default consumption trajectory is assumed to be the result of the maximization problem:

$$
\operatorname{Max} J=\int_{0}^{T} \frac{c(t)^{1-\theta}-1}{1-\theta} e^{-\rho t} d t
$$

\footnotetext{
1 See Hall (1988) who argues for the elimination of the "automatic connection between intertemporal substitution and risk aversion". For a different view on this subject, see Gourinchas and Parker (2002). They use the same parameter to describe consumption patterns over the life cycle: young consumers would save for risk-aversion reasons while older consumers would do so to accumulate assets for retirement.
} 
Subject to: $x^{\prime}(t)=r x(t)+w-c(t) ; x(0)=0 ; x(T)=0$, where $c(t)$ and $x(t)$ represent consumption and net assets at time $t$, respectively; $T$ is his/her expected lifetime, assumed to be equal to the actual number of years left at time zero; $\theta$ is the elasticity of marginal utility of consumption; $\rho$ is his/her pure rate of time preference; $r$ and $w$ are exogenous constants and represent the annual interest rate and the annual wages, respectively.

We have assumed $X(0)=0$ and constant wages, in spite of the fact that assets may be positive at time zero and that wages follow a lifetime pattern which is typically not constant ${ }^{2}$. This is done with no loss of generality. w just represents the "equivalent lifetime wage" which gives the same present value at the time of marriage as the one obtained by integrating the present value of the actual wage trajectory and adding the assets at time zero. Thus, $\int_{0}^{T} w e^{-r t} d t=x(0)+\int_{0}^{T} w(t) e^{-r t} d t$ where $w(t)$ is the actual wage trajectory and $x(0)$ the actual value of assets at time zero.

In this Ramsey-Koopmans type model, consumption will grow, as has been shown extensively in the literature ${ }^{3}$, at an annual rate equal to $\frac{r-\rho}{\theta}$, so that:

$$
c(t)=C_{1} e^{\left[\frac{r-\rho}{\theta}\right] t}
$$

where

$$
C_{1}=\frac{\left[\frac{w e^{r T}-w}{r}\right]\left[\frac{r-\rho}{\theta}-r\right]}{e^{\left[\frac{r-\rho}{\theta}\right] T}-e^{r T}}
$$

$C_{1}$ is the constant which equates the present value of consumption, growing at the optimal rate of growth, to the present value of earnings, both discounted at the interest rate $r$.

It is possible to show, after some algebra, that:

$$
J^{*}=\frac{C_{1}^{1-\theta}}{1-\theta} \frac{e^{\left[\frac{r-\rho}{\theta}-r\right] T}-1}{\left[\frac{r-\rho}{\theta}-r\right]}+\frac{e^{-\rho T}-1}{\rho(1-\theta)}
$$

See, for example, Haider and Solon (2006).

3 See, for example, the book by Barro and Sala-i-Martin (2003). 
This is the value, in utils, that the single individual places on his/her consumption trajectory.

\section{The Married Individual}

The question now is how rich, in terms of equivalent annual wages, should the spouse be in order to maintain the utility value of market goods.

To answer this question, we will assume, only for simplicity, that there are no economies of scale in household production, in spite of well documented evidence on the contrary 4 . In fact, economies of scale are possibly the main economic reason why people get married. What this paper will show is that economies of scale are at least partially compensated when couples differ in their utility functions.

Under the assumption of no economies of scale, if two people with identical tastes, income and wealth get married, consumption costs would simply double and individual consumption-utility levels would not change after marriage.

In what follows, we will assume that spouse-1 has equivalent annual earnings equal to $\mathrm{w}$, as before, and that spouse-2 has equivalent annual earnings equal to $\beta w$. They differ also in their tastes, both in the time preference parameter, $\rho$, and in the aversion to variability in consumption, as expressed in the parameter $\theta^{5}$.

Additionally, we will assume that they have agreed to follow the same consumption path, each consuming half the total in each moment. It is difficult to have one spouse consume more, and then less, than the other at different points in time. They have also agreed, as a result of negotiation, to maximize the sum of their utilities to determine their joint consumption path. For simplicity, we have assumed no children in the model.

Thus, they will maximize:

$$
\operatorname{Max} J_{1}+J_{2}=\int_{0}^{T} \frac{c(t)^{1-\theta_{1}}-1}{1-\theta_{1}} e^{-\rho_{1} t} d t+\int_{0}^{T} \frac{c(t)^{1-\theta_{2}}-1}{1-\theta_{2}} e^{-\rho_{2} t} d t
$$

Subject to: $x^{\prime}(t)=r x(t)+(1+\beta) w-2 c(t) ; x(0)=0 ; x(T)=0 . c(t)$ represents each spouse's consumption path and $x(t)$ represents the couple's net assets at time $t . T$ is their lifetime together, assumed to be exactly equal to the couple's life expectancy at the time of marriage ${ }^{6} ; \theta_{1}$ and $\theta_{2}$ represent their elasticities of marginal utility of consumption (assuming isoelastic utility functions); $\rho_{1}$ and $\rho_{2}$ represent their pure rates of time preference; $r$ and $w$ are exogenous constants and represent the annual

\footnotetext{
See, for example, Browning, Chiappori and Lewbel (2013).

For a review on gender differences in preferences, see Croson and Gneezy (2009).

$6 \mathrm{~T}$ is the time horizon for the couple as such. This means that the time between the deaths of the first and second spouse is considered outside of the model presented here. Alternatively, consumption during that time for the surviving spouse is assumed to be financed with earnings not brought into the marriage.
} 
interest rate and spouse-1's annual wages. Notice that the couple's annual earnings now equal $(1+\beta) w$.

After solving the corresponding Hamiltonian, the optimal consumption trajectory is found to satisfy:

$$
c(t)^{-\theta_{1}} e^{\left(r-\rho_{1}\right) t}+c(t)^{-\theta_{2}} e^{\left(r-\rho_{2}\right) t}=A
$$

where $A$ is a constant satisfying the condition that $x(0)=x(T)=0$.

Differentiation of Equation (6) implies that the growth rate of $c(t)$ is equal to:

$$
\frac{c_{t}^{\prime}}{c_{t}}=\frac{\left(r-\rho_{1}\right) e^{\left(r-\rho_{1}\right) t} c_{t}^{-\theta_{1}-1}+\left(r-\rho_{2}\right) e^{\left(r-\rho_{2}\right) t} c_{t}^{-\theta_{2}-1}}{e^{\left(r-\rho_{1}\right) t} \theta_{1} c_{t}^{-\theta_{1}-1}+e^{\left(r-\rho_{2}\right) t} \theta_{2} c_{t}^{-\theta_{2}-1}}
$$

The rate of growth in consumption is not constant in the married-couple case, as it was in the single-individual case. This is because the sum of isoelastic utility functions is not isoelastic. It is, nevertheless, a weighted average of $\frac{\left(r-\rho_{1}\right)}{\theta_{1}}$ and $\frac{\left(r-\rho_{2}\right)}{\theta_{2}}$ with
weights adding to one but varying through time.

Weights are not independent of the scale in which consumption is measured (dollars or thousands of dollars, for example). We have scaled $c(t)$ in such a way that the average annual rate of growth in consumption equals the simple average of $\frac{\left(r-\rho_{1}\right)}{\theta_{1}}$ and $\frac{\left(r-\rho_{2}\right)}{\theta_{2}}$ during the full period from $t=0$ to $t=T$.

\section{THE DATA}

This section presents the different parameters and variables involved in the model.

To determine a value for the interest rate, in real terms, the Long Term Real Rate Average was used, as published by the U. S. Department of the Treasury (2017). The Long-Term Real Rate Average is the unweighted average of bid real yields on all outstanding TIPS with remaining maturities of more than 10 years and is intended as a proxy for long-term real rates. The unweighted daily average of $1.58 \%$ for the last 15 years ending on June 30, 2017 was used.

To estimate $T$, the assumption is that the single individual is considering marriage for the first time. According to the United States Census Bureau (2016), the median age at first marriage is, as of 2016, 29.5 in the case of men, and 27.4 in the case of women. Using the actuarial life tables for men and women presented by the United States Social Security Administration (2014) for the Social Security area population, a "couple's life expectancy", when he is 30 and she is 27 (rounded to nearest full year), is 43.45 years. This is the expected time until the first of them dies. T will be set at 43.45 years, assuming they marry until death do them part. 
Annual wages were obtained from the Occupational Employment Statistics Survey, of the Bureau of Labor Statistics of the Department of Labor of the United States (2016). The median cross-industry national annual wage is estimated at US\$ 37.040 in May 2016.

To this number, we must add the equivalent annual wage corresponding to net assets at $t=0$. To estimate net assets at $t=0$, we used the data from the Survey of Consumer Finances, of the United States Federal Reserve Board (2013). Family median net worth -the difference between families' gross assets and their liabilities- for the year 2013, was estimated at US\$ 10,400, when the head of household was under 35 years of age. We simply divided this value by two to get each spouse-to-be's net worth at the time of marriage. The corresponding annual wage, using $r=1.58 \%$ and $T=43.45$, consistent with the numbers above, is 165 dollars.

We will set $\mathrm{w}$ at US\$37,205, adding the two components described.

For the parameter $\theta$, or elasticity of marginal utility of consumption, descriptive and normative approaches have been tried in the literature with correspondingly different results ${ }^{7}$. The European Commission (2008) estimates values, for selected European countries, ranging from 1.12 (Poland) to 1.79 (Italy). The Stern Review (2007) sets this parameter at 1 . Cowell and Gardiner (1999) consider the range 0.5 to 4 to be reasonable, while Pearce (2003) proposes values within the 0.5 to 1.2 range. Finally, Zhuang, et al. (2007), in a survey of the theory and practice in the choice of social discount rates for cost-benefit analysis, cite different studies, with a range of empiricial estimates of the elasticity of marginal utility of consumption going from 0.2 to 4 . We will use a range from 0.2 to 4 , to include all the above estimates.

For a range of the parameter $\rho$, or pure rate of time preference, the estimates by the European Commission ${ }^{8}$ for selected European countries, go from $0.9 \%$ (France) to $1.4 \%$ (Hungary). Florio and Sirtori (2013), in a study of 20 European Union countries, estimate the pure rate of time preference in the range from 0.63 (Ireland) to 1.29 (Hungary). The Stern Review ${ }^{9}$ sets this parameter at $0.1 \%$. Finally, Zhuang, et al. ${ }^{10}$, cite different studies, with a range of empiricial estimates of the utility discount rate going from $0.1 \%$ to $2.2 \%{ }^{11}$. We will use a range from $0.1 \%$ to $2.2 \%$, to include all the above estimates.

It should be noted that the above estimates for $\theta$ and $\rho$ are country averages, not values at the individual level. This is why we decided to use the widest possible range, within the limits found in the revised literature.

Table 1 shows a summary of the assumed stylized facts of the model.

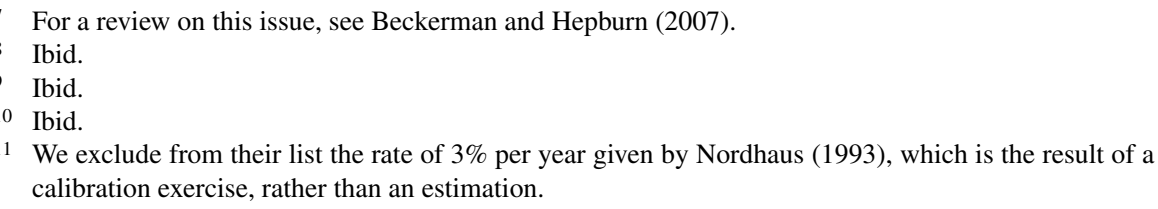




\section{TABLE 1}

ASSUMED STYLIZED FACTS

\begin{tabular}{|l|c|c|}
\hline & Parameter & Value \\
\hline Interest rate & $\mathrm{R}$ & $1.58 \%$ \\
Time horizon & $\mathrm{T}$ & 43.45 years \\
Annual wages & $\mathrm{W}$ & 37,205 dollars \\
Elasticity of marginal utility of consumption & $\theta$ & $0.2-4.0$ \\
Pure rate of time preference & $\mathrm{r}$ & $0.1 \%-2.2 \%$ \\
\hline
\end{tabular}

With these parameters, the single-individual optimal annual growth rate in consumption ranges from $-3.1 \%$ (high $\rho$, low $\theta$ ) to $7.4 \%$ (low $\rho$, low $\theta$ ). The extremes both have a low aversion to variability in consumption, $\theta$, since the optimal rate of growth depends positively (negatively) on $\theta$ depending on whether $\rho$ is greater or less than $r$, respectively.

\section{MODEL CALIBRATION AND RESULTS}

The purpose of this paper is to measure how much richer spouse- 2 has to be in order to compensate for the cost, in terms of consumption utility, he/she imposes on spouse-1, due to his/her differences in the pure rate of time preference and/or the degree of relative aversion to variability in consumption over time.

If both spouses have the same pure rate of time preference and degree of aversion to variability in consumption, then spouse- 2 will have to have the same income as spouse- 1 for spouse- 1 to have the same consumption utility as when being single. In this case, $\beta=1$.

In what follows, we will determine $\beta$ for a highly patient/impatient individual who considers marrying a highly impatient/patient individual. We will assume that both spouses-to-be have a low aversion to variability in consumption, in order to work with the biggest possible difference in the rates of growth each considers optimal.

As mentioned before, consumption was scaled so that the average annual rate of growth in consumption equals the simple average of $\frac{\left(r-\rho_{1}\right)}{\theta_{1}}$ and $\frac{\left(r-\rho_{2}\right)}{\theta_{2}}$ during the full period from $t=0$ to $t=T$. The average rate of growth in consumption between spouses at the opposite ends is $2.15 \%$ ( $-3.1 \% \%$ and $7.4 \%$ as mentioned above).

Equation (7) was solved numerically using the Runge-Kutta method, fixing $c_{t}$ at $t=0$ with this scale-related restriction.

Couple's earnings $(w+\beta w)$ was then calculated so that the present value of earnings equals the present value of consumption, at the interest rate of $1.58 \%$ used. This procedure scales earnings to the same units as consumption. 
We then solved for $\mathrm{w}$ in the individual maximization problem so that $J^{*}$ in equation (4) equals $J_{1} *$ in equation (5). Integration of $J_{1}$ in equation (5) was done using Simpson's Method, with $d t=T / 5,000$.

$\beta$ was then calculated for the two extreme cases: $\left(\rho_{1} ; \theta_{1} ; \rho_{2} ; \theta_{2}\right)=(0.1 \% ; 0.2$; $2.2 \% ; 0.2)$ and $(2.2 \% ; 0.2 ; 0.1 \% ; 0.2)$.

In the first case, $\beta=1.0462$, meaning that the patient individual (who has a low aversion to variability in consumption), requires that the impatient spouse-to-be (who has also a low aversion to variability in consumption) earn at least $4.62 \%$ more than him/her to maintain the utility level he/she had as a single individual. At annual wages of US $\$ 37,205$, this amounts to 1,717 dollars annually, or 53,983 dollars in present-value terms.

Numbers change drastically in the second case, where $\beta=1.1324$, meaning that the impatient spouse requires that the spouse-to-be earns at least $13.24 \%$ more than $\mathrm{him} / \mathrm{h}$ er to maintain the utility level he/she had as a single individual. At annual wages of US $\$ 37,205$, this amounts to US\$ 4,926 dollars annually, or 154,859 dollars in present-value terms.

\section{FINAL REMARKS}

This paper has shown that it is possible to estimate the cost that an individual's impatience, or aversion to variability in consumption, imposes on a patient partner, by using a Ramsey-Koopmans type model which analyzes a marriage decision.

If they do marry, in spite of these differences, there are at least two possible explanations:

There are economies of scale in household production. Browning, Chiappori and Lewbel ${ }^{12}$ find that two singles require about 50 percent more total expenditure than a couple to buy the same equivalent consumption levels. This represents, according to them, an upper bound. Part of these economies of scale would be taken away if spouses differ in their rates of time preference and/or their aversion to variability in consumption.

If there were no economies of scale, as assumed here, then, if they do marry in spite of their differences in the degree of impatience or aversion to variability in consumption, it is because non-consumption utility is increased when doing so. At a minimum in this case, non-consumption utility associated to marriage, including love for each other, would be valued at the numbers derived above.

12 Ibid. 
The framework proposed should also be useful when analyzing business partnerships where one partner is interested in short-term dividends and the other in long-term investments.

\section{REFERENCES}

BARRO, R. J. and X. SALA-I-MARTIN (2003). Economic Growth, Second Edition, The MIT Press.

BECKERMAN, W. and C. HEPBURN (2007). "Ethics of the Discount Rate in the Stern Review on the Economics of Climate Change". World Economics, Vol. 8, No. 1, January March, pp. 187-210.

BROWNING, M.; P. CHIAPPORI and A. LEWBEL (2013). "Estimating Consumption Economies of Scale, Adult Equivalence Scales, and Household Bargaining Power". Review of Economic Studies, Vol. 80, Issue 4, 1267-1303.

COWELL, F. A. and K. GARDINER (1999). Welfare Weights. STICERD, London School of Economics, August.

CROSON, R. and U. GNEEZY (2009). "Gender Differences in Preferences". Journal of Economic Literature, 47:2, 448-474.

EUROPEAN COMMISSION, DIRECTORATE GENERAL REGIONAL POLICY (2008). Guide to Cost Benefit Analysis of Investment Projects.

FLORIO, M. and E. SIRTORI (2013). "The Social Cost of Capital: Recent Estimates for the EU Countries. Centre for Industrial Studies". Working Paper No. 03/2013.

GOURINCHAS, Pierre-Olivier and Jonathan A. PARKER (2002). "Consumption over the Life Cycle". Econometrica, Vol. 70, No. 1 (January), pp. 47-89.

HAIDER, S. and G. SOLON (2006). "Life-Cycle Variation in the Association between Current and Lifetime Earnings". American Economic Review, Vol. 96, No. 4 (September).

HALL, R. E. (1988). "Intertemporal Substitution in Consumption”. Journal of Political Economy, Vol. 96, No. 2 (April), pp. 339-357.

PEARCE, D. W. (2003). "The Social Cost of Carbon and its Policy Implications". Oxford Review of Economic Policy, vol. 19, No. 3, pp. 362-384.

STERN, N. (2007). The Economics of Climate Change: The Stern Review, Cambridge University Press.

UNITED STATES CENSUS BUREAU (2016). Historical Marital Status Tables. https://www.census.gov/ data/tables/time-series/demo/families/marital.html (accessed on July 20, 2017).

UNITED STATES DEPARTMENT OF LABOR, Bureau of Labor Statistics. https://www.bls.gov/oes/ tables.htm (accessed July 20, 2017).

UNITED STATES FEDERAL RESERVE BOARD (2013). Changes in U. S. Family Finances from 2010 to 2013: Evidence from the Survey of Consumer Finances.

UNITED STATES SOCIAL SECURITY ADMINISTRATION (2014). Actuarial Life Tables. https://www. ssa.gov/oact/STATS/table4c6.html (accessed on July 20, 2017).

UNITED STATES DEPARTMENT OF THE TREASURY. https://www.treasury.gov/resource-center/datachart-center/interest-rates/Pages/TextView.aspx?data=reallongtermrateAll (accessed July 17, 2017).

ZHUANG, J., L. ZHIHONG, T. LIN and F. DE GUZMÁN (2007). Theory and Practice in the Choice of Social Discount Rate for Cost-Benefit Analysis: a Survey, Asian Development Bank, ERD Working Paper, No. 94. 
